\title{
Wheat Gene TaATG8j Contributes to Stripe Rust Resistance
}

\author{
Md. Abdullah-Al Mamun 1,2, Chunlei Tang ${ }^{1}$, Yingchao Sun ${ }^{1}$, Md. Nazrul Islam ${ }^{1,3,4}$, Peng Liu ${ }^{1}$, \\ Xiaojie Wang 1 (iD) and Zhensheng Kang ${ }^{1, * \text { (iD }}$ \\ 1 State Key Laboratory of Crop Stress Biology for Arid Areas and College of Plant Protection, \\ Northwest A\&F University, Yangling 712100, China; mamunrwrc@yahoo.com (M.A.-A.M.); \\ tclbad@163.com (C.T.); sycresearch@sina.com (Y.S.); mnislam30@yahoo.com (M.N.I.); \\ Wood319@126.com (P.L.); wangxiaojie@nwsuaf.edu.cn (X.W.) \\ 2 Regional Wheat Research Centre, Bangladesh Agricultural Research Institute, Shyampur, \\ Rajshahi-6212, Bangladesh \\ 3 Key Laboratory of Integrated Pest Management on the Loess Plateau of Ministry of Agriculture, \\ Northwest A\&F University, Yangling 712100, China \\ 4 Agrochemical and Environmental Research Division, Institute of Food and Radiation Biology, \\ Atomic Energy Research Establishment, Bangladesh Atomic Energy Commission, Ganakbari, Savar, \\ Dhaka-1349, Bangladesh \\ * Correspondence: kangzs@nwsuaf.edu.cn; Tel.: +86-29-8708-0061 (ext. 0086)
}

Received: 20 May 2018; Accepted: 1 June 2018; Published: 5 June 2018

\begin{abstract}
Autophagy-related 8 (ATG8) protein has been reported to be involved in plant's innate immune response, but it is not clear whether such genes play a similar role in cereal crops against obligate biotrophic fungal pathogens. Here, we reported an ATG8 gene from wheat (Triticum aestivum), designated TaATG8j. This gene has three copies located in chromosomes 2AS, 2BS, and 2DS. The transcriptions of all three copies were upregulated in plants of the wheat cultivar Suwon 11, inoculated with an avirulent race (CYR23) of Puccinia striiformis f. sp. tritici (Pst), the causal fungal pathogen of stripe rust. The transient expression of TaATG8j in Nicotiana benthamiana showed that TaATG8j proteins were distributed throughout the cytoplasm, but mainly in the nucleus and plasma membrane. The overexpression of TaATG8j in N. benthamiana slightly delayed the cell death caused by the mouse apoptotic protein BAX (BCL2-associated X protein). However, the expression of TaATG8j in yeast (Schizosaccharomyces pombe) induced cell death. The virus-induced gene silencing of all TaATG8j copies rendered Suwon 11 susceptible to the avirulent Pst race CYR23, accompanied by an increased fungal biomass and a decreased necrotic area per infection site. These results indicate that TaATG8j contributes to wheat resistance against stripe rust fungus by regulating cell death, providing information for the understanding of the mechanisms of wheat resistance to the stripe rust pathogen.
\end{abstract}

Keywords: Puccinia striiformis f. sp. tritici; virus-induced gene silencing; Triticum aestivum; ATG8; Agrobacterium-mediated transient expression

\section{Introduction}

Plants are subjected to various biotic and abiotic stresses [1]. Upon environmental stimuli, autophagy is upregulated to sense the intracellular stimuli and mount reactions to protect plants from damage [2]. Autophagy, which is also called self-eating, is a catabolic process in eukaryotic cells that cleans up excessive or unwanted cellular components and macromolecules for nutrient recycling [3,4]. Throughout this process, cytoplasmic components, for example, proteins and different organelles, are targeted to either lysosomes/endosomes or vacuoles for degradation inside these compartments [5]. As a highly regulated and dynamic process that degrades dysfunctional or 
unnecessary cellular components, autophagy plays key roles in modulating plant cell homeostasis. Autophagy has been linked to plants' defense responses against microbes, promoting either death or survival [6-8]. Upon destructive necrotrophic fungal infection, autophagy negatively regulates plant defenses, playing an anti-death role to limit the disease lesion [9]. During biotrophic pathogen interactions, autophagy is a part of the defense response $[6,10]$. The silencing of the Autophagy-related protein 6 (ATG)-heterologous protein in wheat blocks the broad-spectrum immunity conferred by Pm21 towards Blumeria graminis f. sp. tritici (Bgt), indicating that autophagy positively regulates the wheat defense response against the powdery mildew fungus [11]. NBR1/Joka2-mediated autophagy plays a positive role in the defense against viral and oomycete pathogens [12]. Thus, autophagy-mediated defense responses affect the dynamics of host-microbe interactions.

ATG protein mediates a degradative process through which damaged or unwanted cellular components are recycled. ATG proteins contain the ubiquitin domain of the Gamma-aminobutyric acid (GABA)-receptor-associate protein (GABARAP), which is a large family of proteins that mediate intracellular membrane trafficking and/or fusion. It contains six predicted tubulin binding sites and three ATG7-binding sites. The mechanisms of autophagy in mammalian and plant cells are evolutionarily conserved [13,14]. To date, more than 35 ATG genes have been recognized in yeast, among which 17 core ATGs are engaged in autophagosome formation $[15,16]$. The lipidation of ATG8 and its position in the membrane are crucial for autophagic membrane extension [17]. Normally, ATG8 is conjugated to the autophagosomal membrane via phosphatidylethanolamine (PE) lipidation [18]. Under autophagy, ATG8 is processed at the C-terminus by ATG4 to expose glycine. The modified ATG8 protein is then conjugated to PE by ATG3 and ATG7 and assembled into autophagosome-resembling structures that are delivered to vacuoles [19]. ATG8 participates in both cytoplasm-to-vacuole transport and autophagy [20]. In plants, the expanded ATG8 protein family members exhibit different expression under different conditions, which may be responsible for the specificity of targeting autophagosomes [21,22]. In Arabidopsis, ATG8 associates with autophagosomal membranes during autophagy [23], and ATG8-mediated autophagy accumulates upon infection with Pto DC3000 (AvrRpm1) [6]. Moreover, the ATG8CL protein is targeted by the Phytophthora infestans effector PexRD54 to reroute the autophagosome to the feeding sites for nutrient uptake [24]. It appears that ATG8-mediated autophagy plays a significant role in plant effector-triggered immunity (ETI) and is targeted by pathogens to attack the host defenses.

Puccinia striiformis f. sp. tritici (Pst) is a biotrophic fungal pathogen that feeds on living wheat cells to uptake nutrients [9]. Wheat-Pst interactions often take place in a gene-for-gene manner. In resistant wheat cultivars, the avirulence ( $A V R$ ) gene of $P s t$ is recognized by a corresponding plant resistance $(R)$ gene, which subsequently activates rapid cell death surrounding the infection sites, known as the hypersensitive response (HR), to limit pathogen growth and spread [25]. Simultaneously, a set of defense reactions, as well as rapid cell death, cell wall strengthening, pathogenesis-related (PR) proteins, and antimicrobial compounds, are also observed [26]. As a typical feature of plant ETI, understanding the HR mechanism will provide new insights into Avr-R-mediated resistance.

Despite the large number of studies on ATG8 in yeasts and animals, little is known for plants, especially modern bread wheat (Triticum aestivum) [27,28]. In this study, a wheat ATG8-heterologous protein, TaATG8j, was isolated from wheat cultivar cv. Suwon 11 (Su11) infected with Pst. The expression pattern and subcellular localization of TaATG8j were investigated. To analyze its role in cell death regulation, TaATG8j was heterologously expressed in Nicotiana benthamiana and Schizosaccharomyces pombe. Furthermore, transient silencing of TaATG8j expression in wheat was performed to analyze the function of TaATG $8 j$ in wheat resistance to Pst. 


\section{Results}

\subsection{Identification and Isolation of the TaATG8j Gene}

Based on the expressed sequence tag (EST) sequence (GenBank Accession No. GR302394.1) from the cDNA library of a compatible wheat-Pst interaction, a 695-bp cDNA sequence with a 360-bp open reading frame(ORF) was obtained from Su11 wheat, which encoded an ATG8-heterologous protein. A BLASTN (Basis Local Alignment Search Tool Neuclitide) search in the Chinese Spring genomic database revealed three copies of this gene in the wheat genome (Figure S1), located on the wheat chromosomes 2AS, 2BS and 2DS. To obtain more information about TaATG8j in the wheat sub-genomes, we downloaded the exon-intron structure and assembled exon sequences, designated TaATG8j-2AS, TaATG8j-2BS and TaATG8j-2DS, respectively (Figure S1 and Table 1). The TaATG8j gene from Su11 shared $99.72 \%, 98.61 \%$ and $98.34 \%$ nucleotide identity with the three copies of TaATG8j-2AS, TaATG8j-2BS and TaATG8j-2DS of Chinese Spring in the ORF region (Figure S1). However, considering the protein sequence, only one amino acid variation was observed in TaATG8j, with the predicted proteins of the three homoeologous genes (Figure S2). Considering exon structure, all three copies of TaATG8j consist same number(five) of exon (Figure S3).

Table 1. Three copies of TaATG8j in the subgenomes of wheat encoding the same TaATG8j protein isolated from the Triticum aestivum cv. Chinese Spring genomic database (Available online: http:/ / plants.ensembl.org).

\begin{tabular}{ccccccc}
\hline \multirow{2}{*}{ Gene } & Chromosomal & cDNA & ORF & Protein & DNA & Identity (\%) ${ }^{\mathbf{a}}$ \\
\cline { 2 - 7 } & Location & Size (bp) & Size (bp) & Size (aa) & Size (bp) & Identity \\
\hline TaATG8j-2AS & 2AS & 731 & 360 & 119 & 2438 & 99.3 \\
TaATG8j-2BS & 2BS & 784 & 360 & 119 & 2746 & 98.4 \\
TaATG8j-2DS & 2DS & 813 & 360 & 119 & 2810 & 98.6 \\
\hline
\end{tabular}

a The percentage of the identity was obtained by comparing the gene DNA sequences of Su11 with wheat genome cv. Chinese Spring.

Plants contain expanded ATG8 family members. Similarly, here, in addition to the TaATG8j gene, we identified nine other ATG8-heterologous proteins in the wheat genome, named TaATG8a- $h$ (GenBank accession numbers KF294807-KF294814), was along with a heterologous protein assembled from 3EST (HX189738, CK196170 and HX250137) sequences [29], designated TaATG8i. Therefore, the ATG8 gene identified in this study was named TaATG8j (Figures 1 and 2). A structural sequence analysis showed that TaATG8j encoded a putative protein of 119 amino acids, with a conserved UBQ (Upiquitin-like) superfamily domain, six (black arrow) predicted tubulin binding sites and three (green arrow) predicted ATG7 binding sites (Figure 2). Multiprotein sequence alignment with other organisms showed that TaATG8j shared the highest identity (95.93\%) with ATG8g from T. aestivum and ATG8 from Triticum dicoccoides. Additionally, TaATG8j shared $82.93 \%, 82.11 \%, 90.24 \%$, and $86.18 \%$ identity with TaATG8a- $f$ from wheat BdATG8 from Brachypodium distachyon, OsATG8 from rice and ZmATG8a from maize respectively. The lowest identity (less than 70\%) was observed for SsATG8 from yeast and TaATG8h-i from wheat (Figure 2).

Phylogenetic analyses indicated two distinct clades that comprised all members of the ATG8 subfamily. Clade 1 comprised plant members including TaATG8j protein, and Clade 2 was related to human ancestors. Most of the paralogs of Oryza sativa (Os), Glycine max (Gm), Arabidopsis thaliana (At) and T. aestivum (Ta) were in Clade 1, but some of their paralogs were also present in Clade 2, indicating that the ancestor of Clade 1 and its descendants frequently duplicated during genomic evolution (Figure 1). The lengths of the branches indicate the closeness of the evolutionary relationships between the ATG8 proteins. 


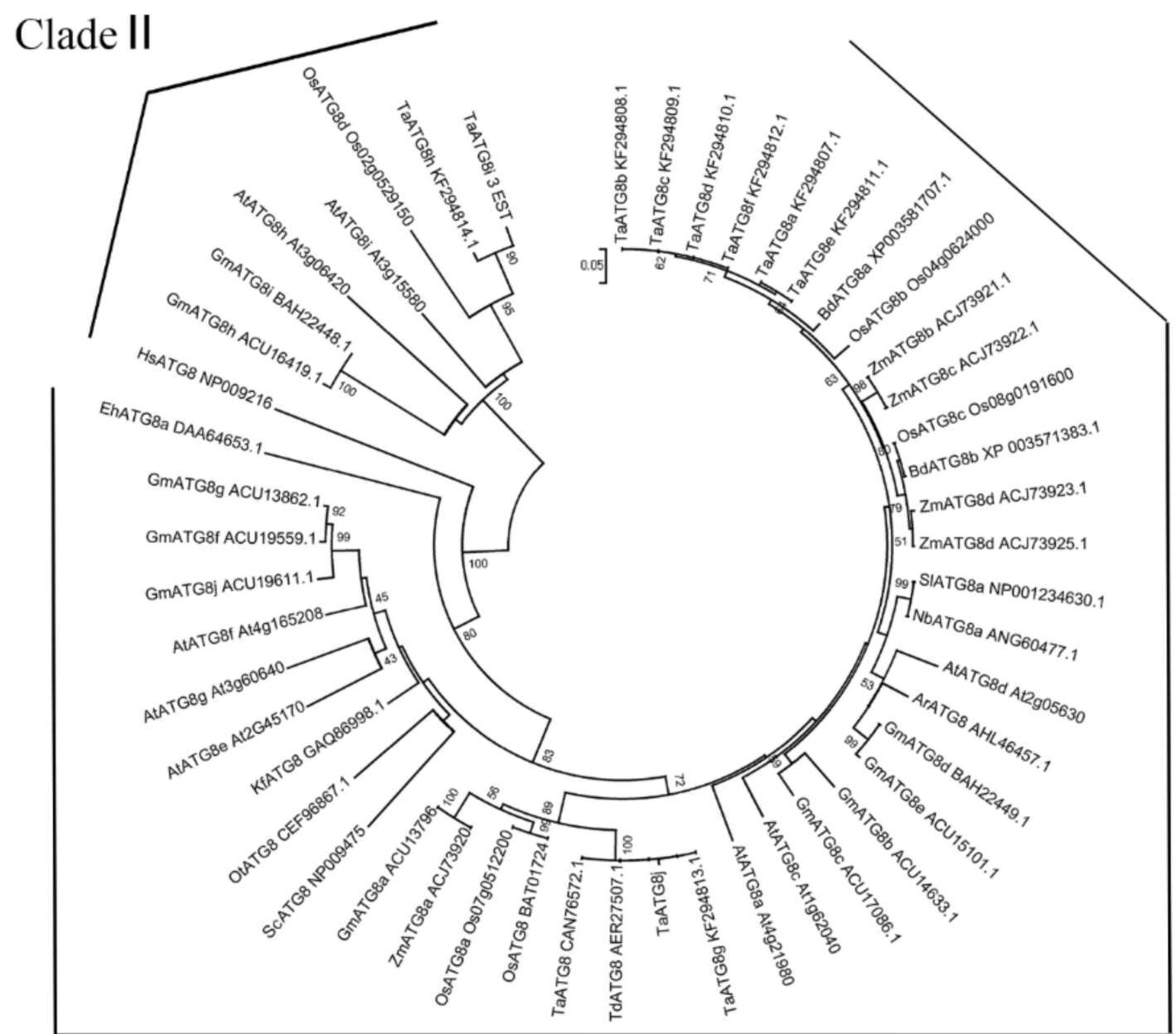

Clade I

Figure 1. Phylogenetic analysis of TaATG8j with other members of ATG8 (autophagy-related 8) family. The phylogenetic tree was constructed using the neighbor-joining method and the software MEGA 7. The internal branches were assessed by bootstrapping values, with 1000 bootstrap replicates, and a branching cut-off of 50\%. The branches are considered protein name, GenBank accession number, and one assembled sequence from three EST (expressed sequence tag) sequences (HX189738, CK196170 and HX250137). Ta: Triticum aestivum; Bd: Brachypodium distachyon; Os: Oryza sativa; Zm: Zea mays; Gm: Glycine max; At: Arabidopsis thaliana; Td: Triticum dicoccoides; Sl: Solanum lycopersicum; $\mathrm{Nb}$ : Nicotiana benthamiana; Kf: Klebsormidium flaccidum; Sc: Saccharomyces cerevisiae; Ot: Ostreococcus tauri; Eh: Emiliania huxleyi; Hs: Homo sapiens. 


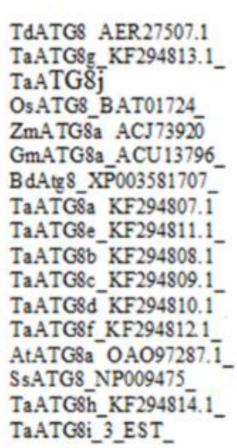

TdATGS_AER27507.1 TaATG8 ${ }_{2}$ KF$_{2} 94813 . \overline{1}$ TaATG 85

OsATG_BATO1724

ZmATG8a ACJ73920

GmATG8a_ACU13796

BdAtg 8 XP 003581707

TaATG8_KF294807.1

TaATGSe KF294811.1

TaATG8b_KF294808.1

TaATGSC KF294809.1

TaATGSd_KF294810.1

TaATG8__KF2948121

AtATG8a OA097287.

Ss.ATG8 NP009475

TaATGSh KF294814. 1

TaATGSi_3_EST_
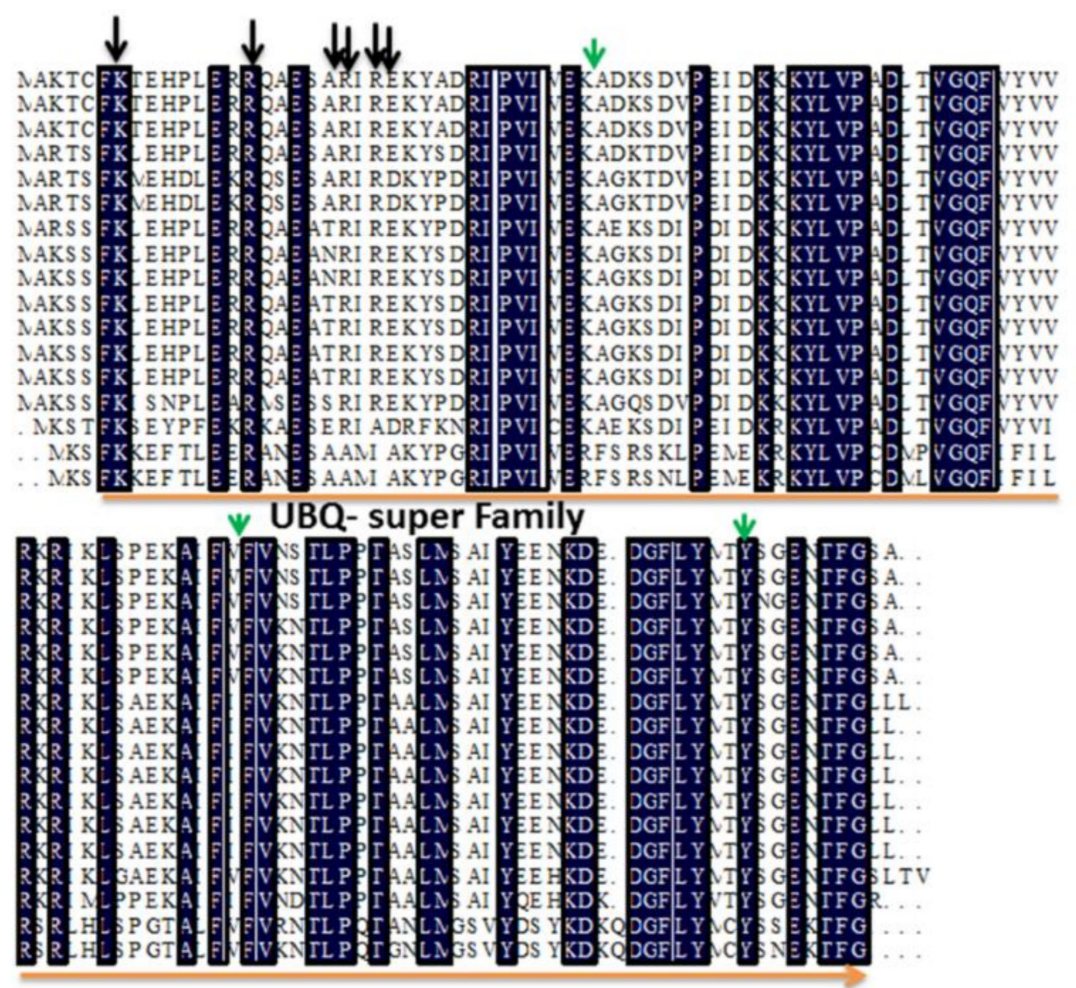

Figure 2. Multiprotein sequence alignment of TaATG8j against other members of the ATG8 family. Identical amino acids are indicated in black. Black and green arrows indicate tubulin- and ATG7-binding sites, respectively. Orange line indicates the upiquitin-like (UBQ) super family protein. Ta: Triticum aestivum; Td: Triticum dicoccoides; Zm: Zea mays; Os: Oryza sativa; Gm: Glycine max; Bd: Brachypodium distachyon; Sc: Saccharomyces cerevisiae; and At: Arabidopsis thaliana.

\subsection{TaATG8j Is Induced upon Incompatible Pst Attack}

To explore the function of TaATG8j in wheat defense to Pst, the transcript level of TaATG8j was quantified in both compatible and incompatible wheat-Pst interactions using different genome-specific primers (Table S1). In the incompatible interaction, the transcripts of all copies of TaATG8j were significantly upregulated (more than 2.0-fold) at 24 hpi compared with the control (0 hpi), although the upregulation level differed slightly. In contrast, the compatible interaction suppressed these copies (Figure 3). These results indicate that all three copies (TaATG8j-2AS, TaATG8j-2BS and TaATG8j-2DS) of TaATG8j were upregulated in the early stage of the incompatible interaction (24 hpi). 


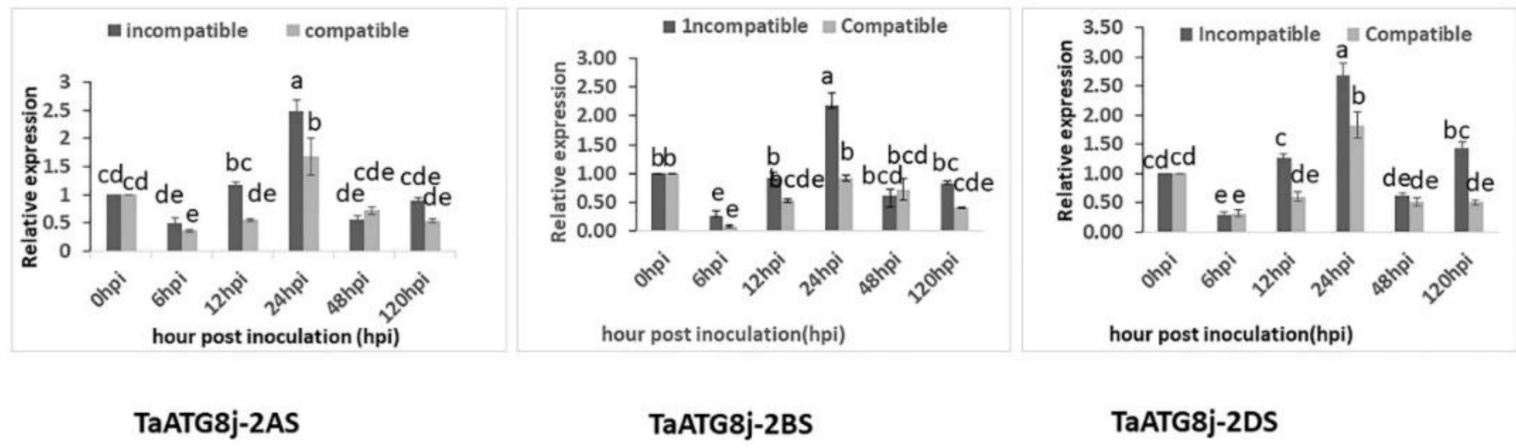

Figure 3. Relative expression levels of the three TaATG8j copies in wheat plants (cv. Suwon 11) inoculated separately with incompatible and compatible pathotypes of Puccinia striiformis $\mathrm{f}$. sp. tritici. The wheat seedlings were inoculated with CYR23 (incompatible) and CYR31 (compatible) and sampled at $0,6,12,24,48$ and $120 \mathrm{hpi}$. The data were standardized to the wheat elongation factor TaEF- $1 \alpha$ gene. The relative expression level of the gene was quantified using the comparative threshold $\left(2^{-\Delta \Delta C t}\right)$ method. Error bars indicate the variation among three replications, and the different letters represent significant differences $(p<0.05)$ by the Tukey HSD (Honestly Significant Difference) test. hpi: hours post-inoculation.

\subsection{Protein TaATG8j Is Distributed throughout the Cytoplasm but Mainly in Nuclei and Plasma Membranes}

The localization of ATG8j proteins on the surface of membranes is necessary for autophagy biogenesis [29]. To determine the subcellular localization of TaATG8j in the leaf tissue of N. benthamiana, recombinant PB-eGFP-TaATG8j was infiltrated into $N$. benthamiana. The empty vector (EV) $\mathrm{P}^{\text {BinGFP2 }-G F P}$ was used as a control. Using DAPI (4',6-diamidino-2-phenylindole) and a hypertonic solution, fluorescence microscopy revealed that GFP-TaATG8j fusion proteins were distributed throughout the cytoplasm, especially the nucleus and plasma membrane (Figure 4A). To confirm this result, we further conducted Western blot to analyze the stability of the TaATG8j fusion protein. We successfully observed stable TaATG8j fusion proteins and EV-PBinGFP2 - GFP proteins at 40 and $27 \mathrm{kDa}$, respectively (Figure 4B).

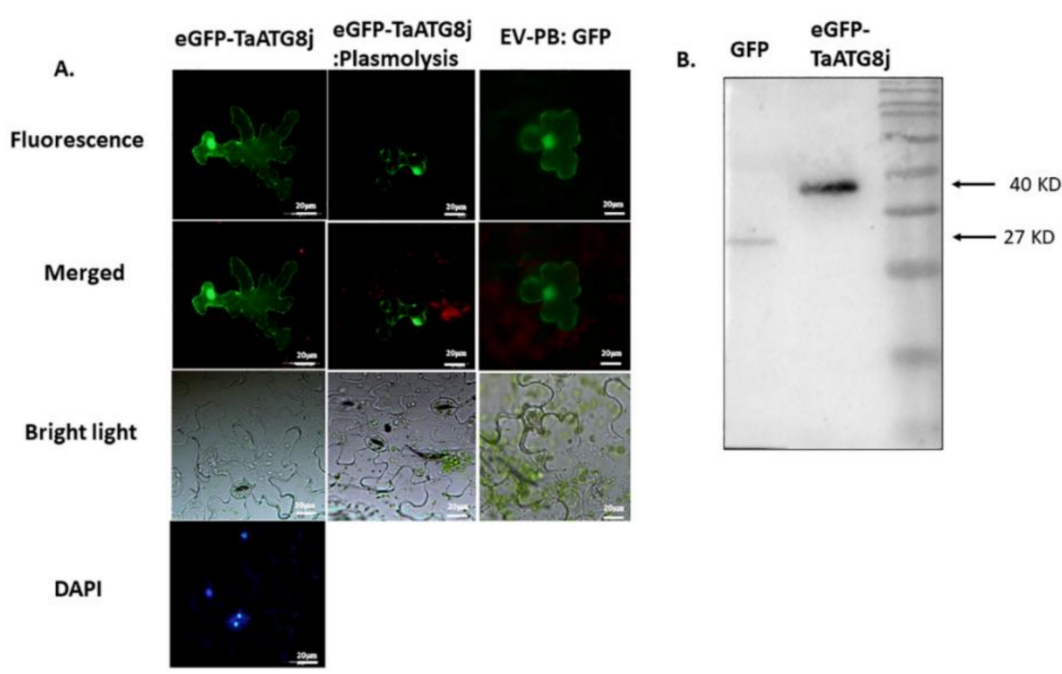

Figure 4. Subcellular localization and immunoblotting of the TaATG8j protein. (A) N. benthamiana leaf tissues were transformed with a plasmid carrying a fusion protein. The picture was obtained using a fluorescence microscope. The left four images indicate eGFP-TaATG8j, the middle three images indicate eGFP-TaATG8j: Plasmolysis, and the right three images indicate EV-PB: GFP (control); (B) Immunoblotting analysis of eGFP-TaATG8j (40 kDa) and EV-GFP (27 kDa). Bar: $20 \mu \mathrm{m}$. 


\subsection{TaATG8j Delays Cell Death Triggered by BAX in N. benthamiana}

To investigate the potential role of TaATG8j in Programmed cell death (PCD), we overexpressed TaATG8j in N. benthamiana through the A. tumefaciens (GV3101)-mediated infiltration assay. EV and Avr1b were used as negative and positive controls, respectively. When expressed alone, EV, Avr1b or TaATG8j did not cause cell death (Figure 5). Five days post-infiltration with $A$. tumefaciens carrying PVX-BAX, obvious cell death was observed in the sites infiltrated with EV, suggesting its cell induction role. When co-expressed with Avr1b, BAX did not cause cell death, indicating that it was suppressed by Avr1b. For TaATG8j, slight cell death was detected at five days after BAX infiltration, while significant cell death was observed at six days post infiltration (Figure 5). These results indicated that TaATG8j alone was not able to induce cell death but rather delayed the cell death triggered by BAX.

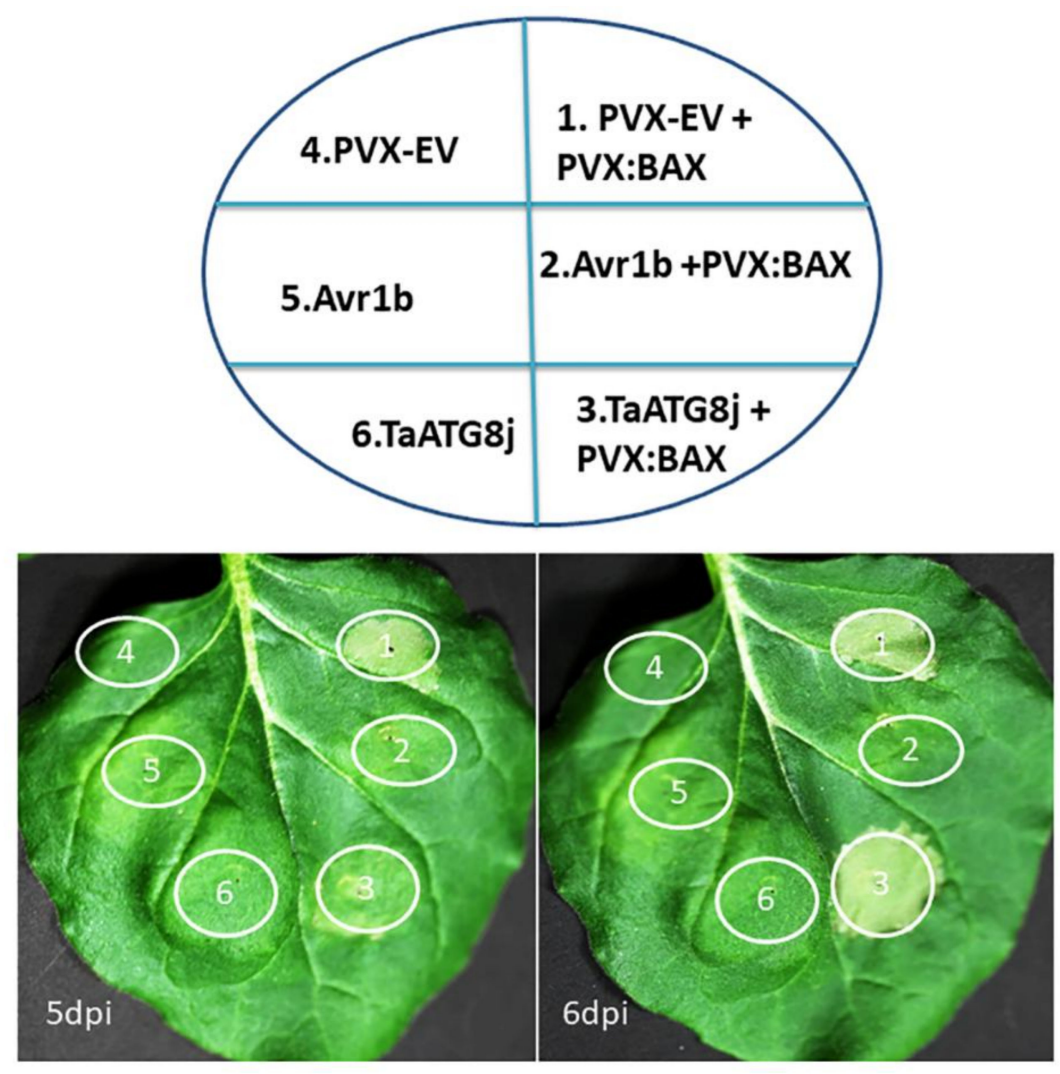

Figure 5. The transient overexpression of TaATG8j in N. benthamiana (Nicotiana benthamiana). Transient overexpression of TaATG8j suppressed the programmed cell death induced by the PVX-BAX gene. The $N$. benthamiana leaf was infiltrated with Agrobacterium tumefaciens cells carrying TaATG8j (circles 3 and 6), Avr1b (circles 2 and 5) or $E V$ (circles 1 and 4). Photographs were taken at 5 and 6 days after the second infiltration (the second infiltration was done only in circles 1, 2 and 3 at $24 \mathrm{~h}$ after the first infiltration using A. tumefaciens carrying $P V X: B A X)$. The circular areas indicate the infiltrated spaces.

\subsection{Overexpression of TaATG8j Induces Cell Death in Yeast}

After overexpression in N. benthamiana cells, we further investigated the roles of TaATG8j in cell death using a fission yeast system. TaATG8j was overexpressed in fission yeast ( $S$. pombe) governed by the nmt promoter, which is suppressed by thiamine (VB). The mouse BAX gene, a pro-apoptotic factor that induces cell death in yeast, and empty pREP3X vector were used as positive and negative controls, respectively [30]. Yeast cells were cultured with $(+\mathrm{VB})$ or without thiamine $(-\mathrm{VB})$, and the cell death phenotype was checked with trypan blue. As shown in Figure 6A, the dead yeast cells were stained blue. The expression of TaATG8j or BAX led to significantly decreased total alive yeast cells in the 
absence of thiamine $(-\mathrm{VB})$ compared to that with thiamine $(+\mathrm{VB})$ throughout the incubation period, whereas the expression of pREP3X did not cause any significant change (Figure 6B). Furthermore, the ratio of dead (stained yeast cells) to total yeast cells was calculated. The results showed that yeast cells expressing $B A X$ incubated without thiamine ( $-\mathrm{VB})$ exhibited significantly more dead cells than those incubated with thiamine $(+\mathrm{VB})$ after 14 to $34 \mathrm{~h}$ of incubation (Figure $6 \mathrm{C})$. Similar results were obtained for TaATG8j, except at 14 and $18 \mathrm{~h}$ after incubation (Figure 6C). However, the yeast cells transformed with empty pREP3X did not exhibit any remarkable change in the ratio of dead cells. These results indicated that the overexpression of TaATG $8 j$ induced cell death in fission yeast.

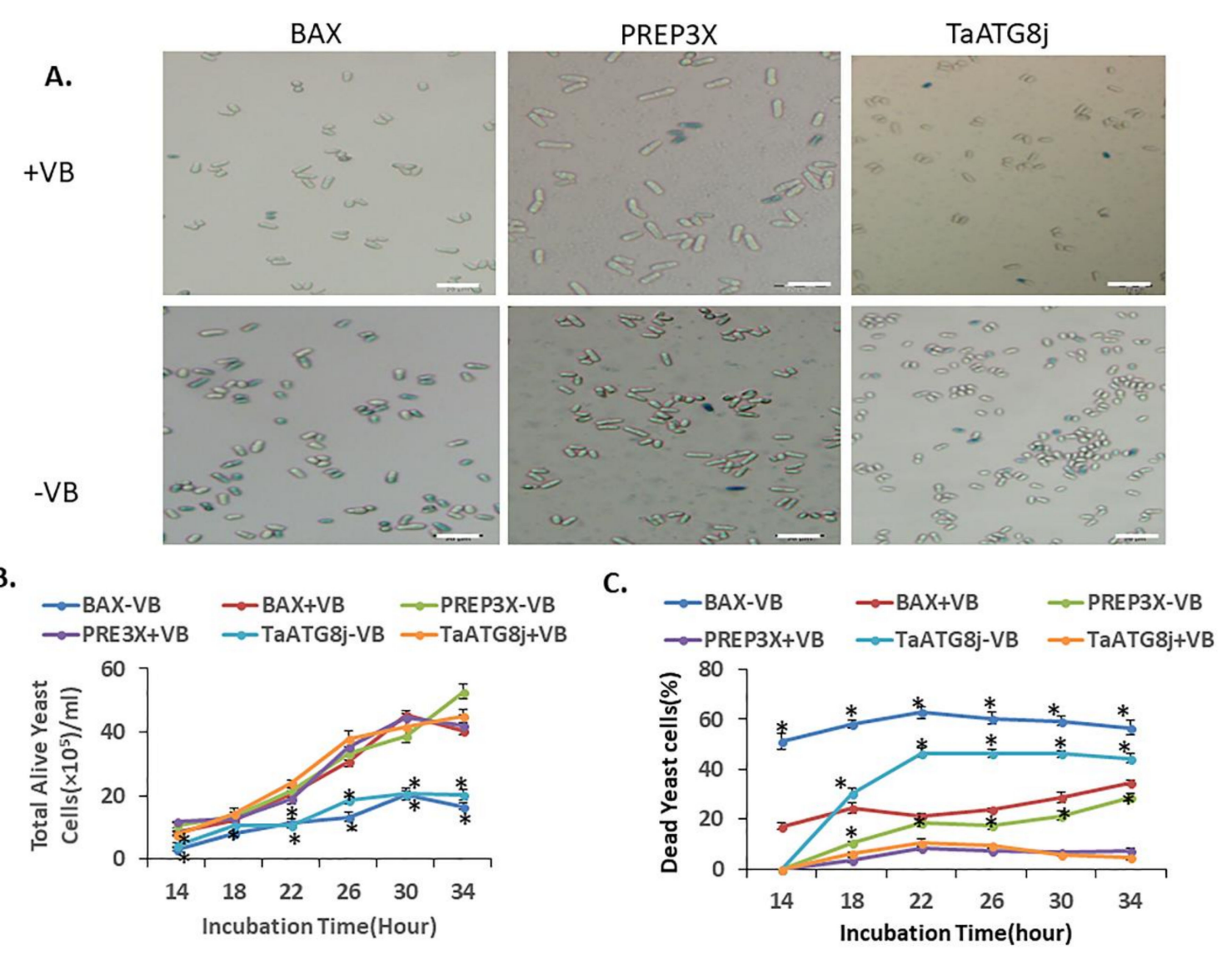

Figure 6. Overexpression of TaATG8j in yeast cells. The mouse pro-apoptotic BAX gene and pREP3X empty vector were used as positive and negative controls, respectively. Thiamine (VB) and trypan blue were used for repression and as a staining medium, respectively. The yeast cells were counted using a hemocytometer. Three biological replicates were performed. The yeast cell number $\mathrm{mL}^{-1}$ was calculated at 14, 18, 22, 26, 30 and $34 \mathrm{~h}$ post-incubation. Incubation was started from an identical $\mathrm{OD}_{600}$ : 0.2 using \pm VB. (A) Phenotypically dead and alive yeast cells were compared by staining trypan blue staining using \pm VB after expressing pREP3X_TaATG8j, pREP3X_BAX, or pREP3X. The dead yeast cells were stained blue. Bar: $20 \mu \mathrm{m}$; (B) The total number of cells $\mathrm{mL}^{-1}$ was counted. Yeast cells expressing the total number of alive and dead yeast cells of TaATG8j and BAX were significantly altered compared to the control; (C) The percentage (\%) of the dead yeast cells of the total cells was calculated. Yeast cells expressing in TaATG8j or BAX showed more cell death compared with the control. Mean data are presented, and error bars indicate the variations among the biological replicates. Asterisks indicate the level $\left({ }^{*} p<0.01\right)$ of significance without thiamine (VB) using Student's $t$-test.

\subsection{Knockdown of TaATG8j Enhances Wheat Susceptibility to Pst}

To study the role of the TaATG8j gene in wheat immunity against Pst in more detail, barley stripe mosaic virus (BSMV)-mediated gene silencing (VIGS) was used to silence TaATG8j. Due to 
the high similarity between the three copies, the two fragments used for silencing resulted in the silencing of the three copies together (Figure S1). Wheat seedlings inoculated with BSMV:TaATG8j-1s, BSMV:TaATG8j-2s and BSMV: $\gamma$ exhibited mild chlorotic mosaic symptoms on the third or fourth leaves at $13 \mathrm{dpi}$, while the seedlings inoculated with BSMV:TaPDS displayed strong photobleaching symptoms (Figure 7A). These results suggest that the BSMV-VIGS system functioned accurately. Fifteen days post-inoculation with the Pst pathotype CYR23, apparent HR was observed on the fourth leaves of the BSMV:TaATG8j-knockdown wheat seedlings. Sporadic fungal sporulation was observed around the necrotic spots at $18 \mathrm{dpi}$ (Figure 7D). In contrast, inoculation with the Pst pathotype CYR31 resulted in normal disease development with no remarkable change (Figure 7C).

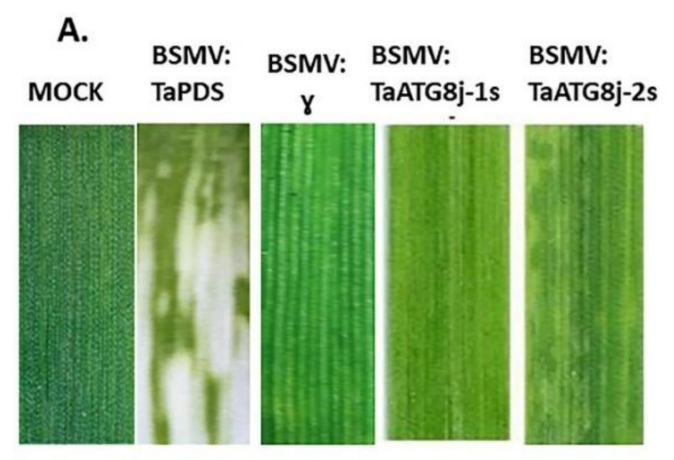

B.
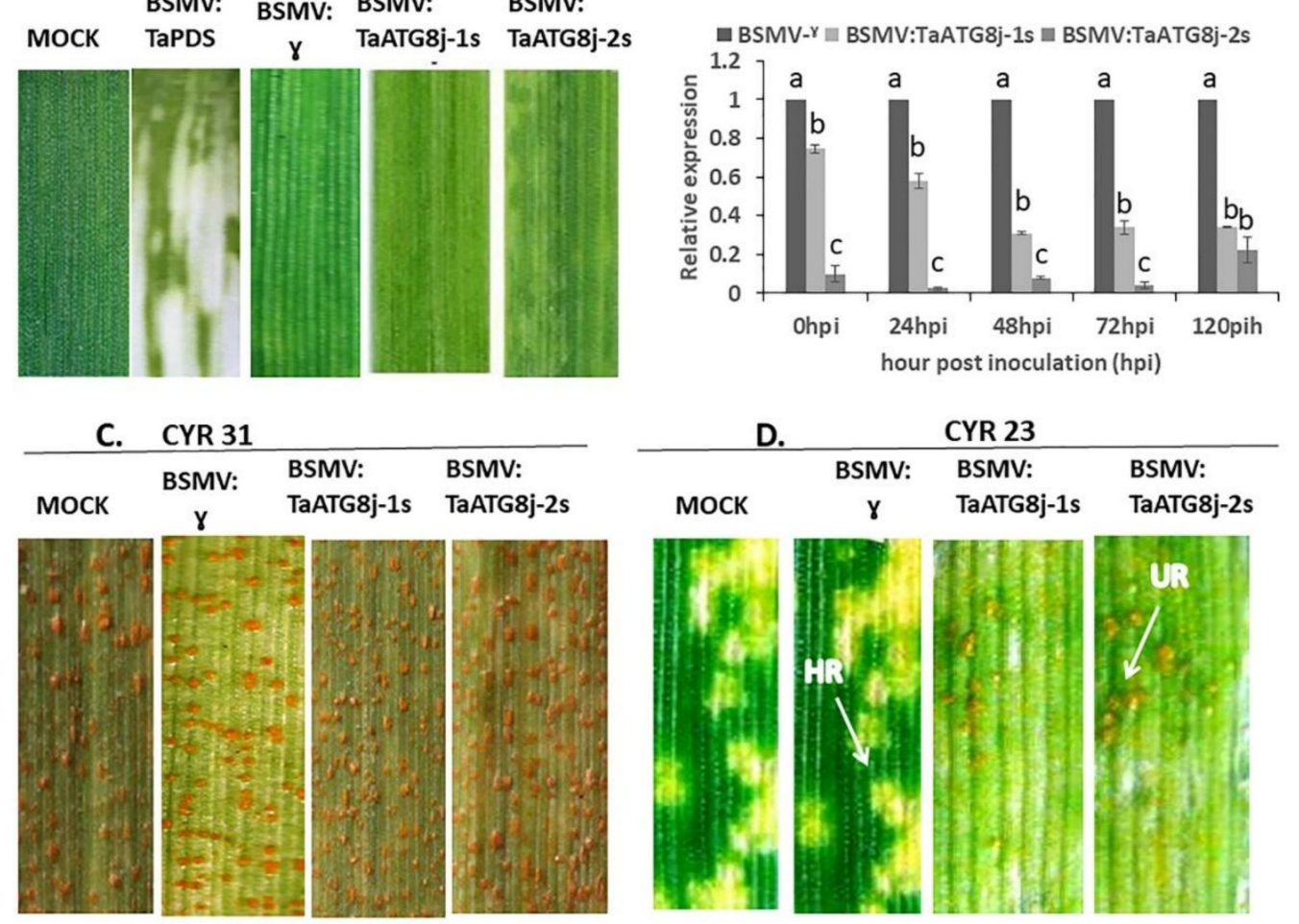

Figure 7. Functional activities of the TaATG8j gene mediated by BSMV (Barley Stripe Sosaic Virus) mediated gene silencing during the interaction between wheat and Puccinia striiformis $\mathrm{f}$. sp. tritici. Wheat seedlings were inoculated by recombinant BSMV:TaPDS, BSMV: $\gamma$, BSMV:TaATG8j-1s or BSMV:TaATG8j-2s on the second leaves, followed by inoculation with Pst pathotype CYR23 (avirulent) or CYR31 (virulent) on the fourth leaves. (A) Slight chlorotic mosaic symptoms appeared on the fourth leaves of wheat seedlings in recombinant BSMV: $\gamma$, BSMV:TaATG8j-1s and BSMV:TaATG8j-2s at 13 dpi. Mock leaves were treated only with FES buffer; (B) Relative transcription levels of TaATG8j in silenced plants after inoculation with CYR23. The data were standardized with the wheat elongation factor gene $(T a E F-1 \alpha)$. Error bars indicate the variation among the three replications, and different letters indicate significant differences $(p<0.05)$ by the Tukey HSD test; $(\mathbf{C}, \mathbf{D})$ Photographs of the fourth leaves at $18 \mathrm{dpi}$, which were further inoculated by fresh urediniospores of the virulent strain CYR31 and the avirulent strain CYR23.

qRT-PCR analyses showed that the expression of both fragments was significantly reduced in TaATG8j-knockdown plants compared with control plants (Figure 7). Considering BSMV: $\gamma$, the highest silencing efficiency was observed with the BSMV:TaATG8j-2s fragment at all time points (more than $80 \%$ ), and the BSMV:TaATG8j-1s fragment was also significantly silenced. These results indicated that the TaATG8j gene was effectively silenced in the incompatible interaction, and after silencing the TaATG8j gene, the resistant wheat cultivar cv. Su11 became susceptible. 


\subsection{Suppression of Defense-Related Genes in TaATG8j-Knockdown Plants}

At the time of plant pathogenic infection, the production of $P R$ proteins in the uninfected parts of the plant can prevent the affected plant from further infection [31,32]. Upon the reduced resistance of wheat Su11 to the avirulent Pst CYR23, we further assessed the expression pattern of defense-related genes in TaATG8j-knockdown plants by qRT-PCR. The results showed that the $P R$ protein genes, TaPR1 and TaPR2, were down-regulated in TaATG8j-1s- and TaATG8j-2s-knockdown plants infected by Pst CYR23, particularly at 48, 72 and 120 hpi (Figure 8 and Figure S4). The expression of the $P R$ protein gene TaSOD was also reduced in the TaATG8j-knockdown plants. This result indicates that the accumulation of defense-related genes was suppressed in TaATG8j-knockdown plants.
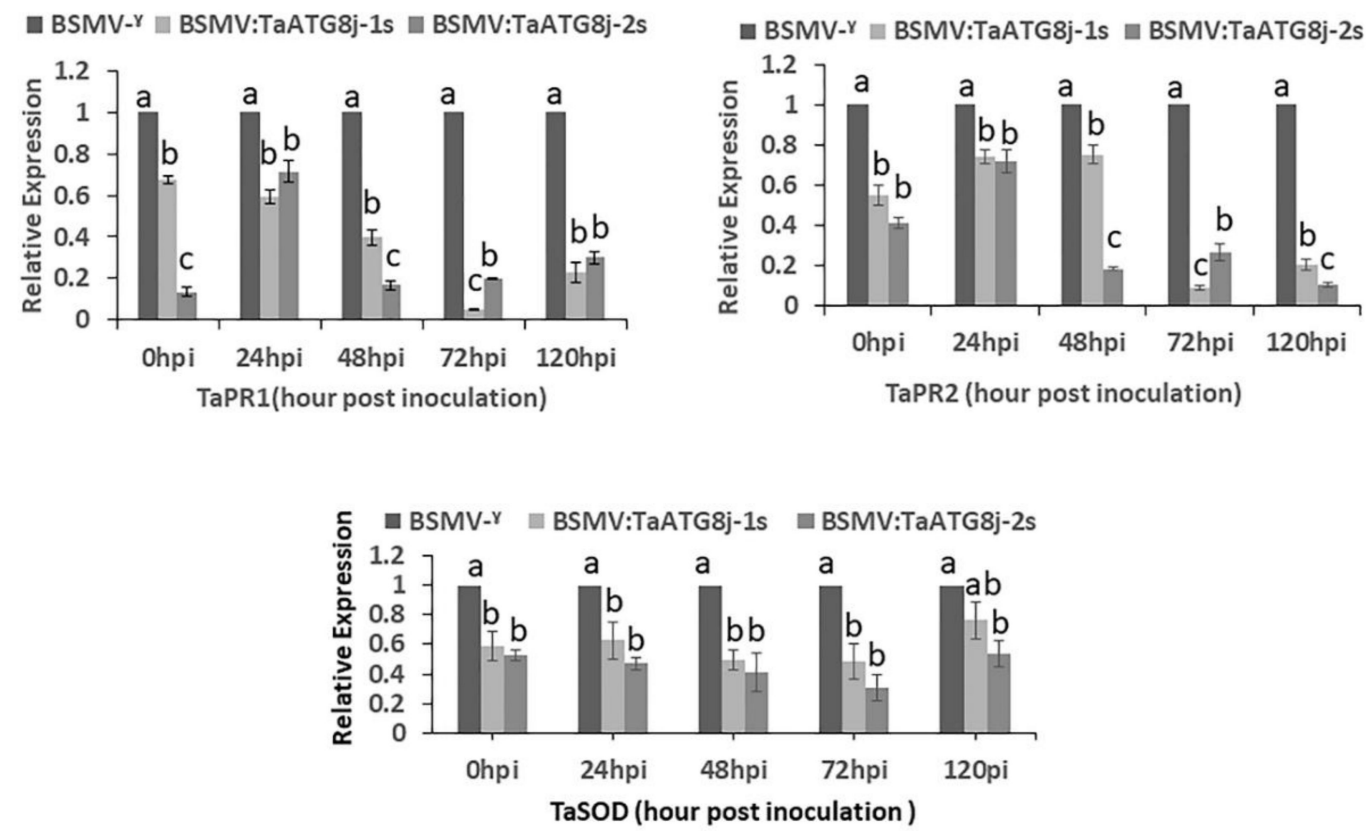

Figure 8. Transcription levels of defense-related genes in response to Puccinia striiformis $\mathrm{f}$. sp. tritici in TaATG8j-silenced plants. The expression of TaPR1, TaPR2 and TaSOD was quantified in TaATG8j-silenced plants compared with the control. The data were standardized to the wheat TaEF-1 $\alpha$ gene. Error bars indicate the variations among the three independent biological replicates. Different letters indicate significant differences $(p<0.05)$ using the Tukey HSD test.

\subsection{Histological Observation of Pst Growth and Host Necrotic Cell Death}

To illustrate the fungal development in TaATG8j-knockdown plants, WGA staining was used to stain the fungal structure. As shown in Figure 9A,B, the TaATG8j-knockdown plants inoculated with CYR23 had significantly longer hyphae than the BSMV: $\gamma$ plants at 24,48 and $72 \mathrm{hpi}$. In addition, the number of branches was significantly increased $(p<0.05)$ by the second knockdown fragment at 24 and $72 \mathrm{hpi}$, and more hyphal branches were observed than in the BSMV: $\gamma$-infected seedlings (Figure 9C). In contrast, the necrotic areas were significantly decreased in first- and second-fragment infected leaves, followed by BSMV: $\gamma$ (Figure 9D). The overall histological results indicated that silencing TaATG8j enhanced the susceptibility of the Su11 cultivar to Pst and permitted enhanced hyphal growth and branching.

\subsection{Increased Fungal Biomass in TaATG8j-Knockdown Plants}

To assess the fungal mycelium growth in TaATG8j-silenced plants, total genomic DNA was extracted to quantify the fungal biomass using qRT-PCR. At $18 \mathrm{dpi}$, in TaATG8j-knockdown seedlings infected by Pst CYR23, the fungal content in wheat tissues was significantly $(p<0.05)$ increased 
compared with that in the control plants. Relatively more abundant fungal biomass was identified in TaATG8j-2s-knockdown plants than that in the TaATG8j-1s-knockdown plants, which may have been due to the higher silencing efficiency of the second fragment than the first fragment (Figure 10).

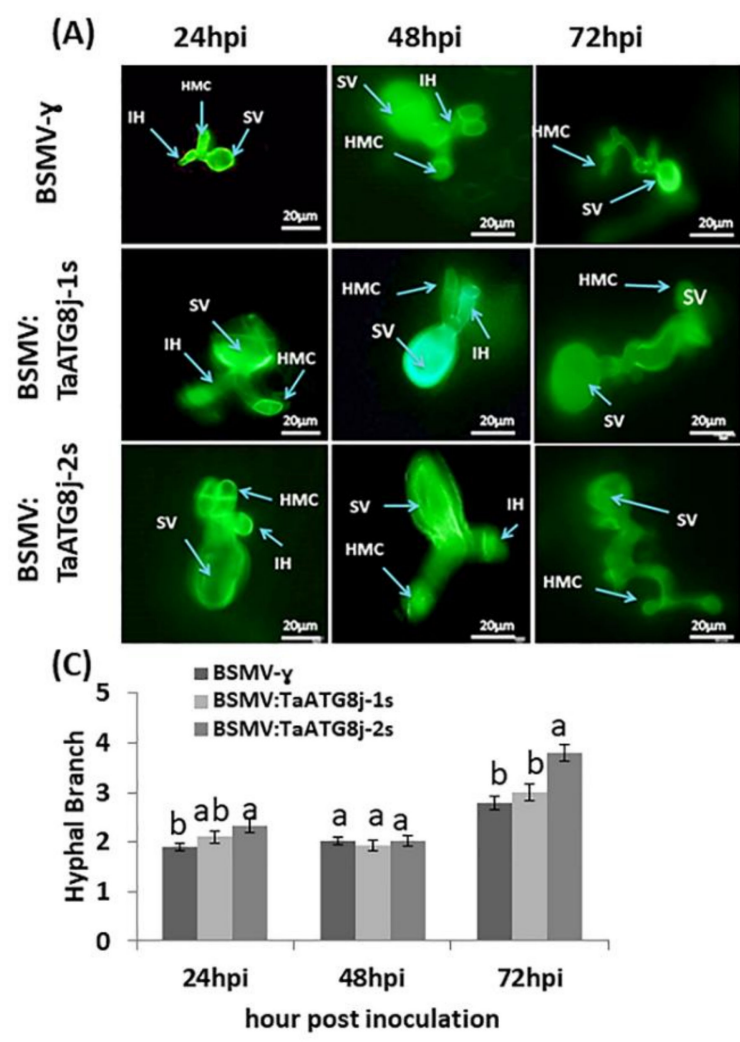

(B)

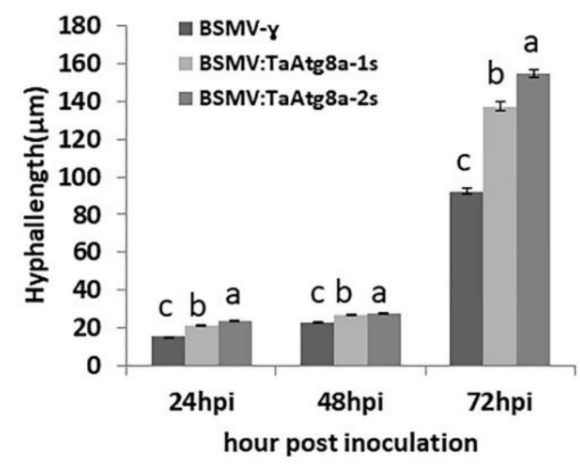

(D)

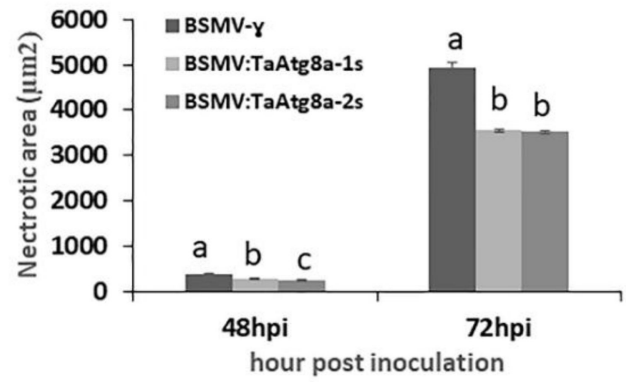

Figure 9. Histological observation of TaATG8j-silenced plants challenged with the avirulent Pst pathotype CYR23. After removing chlorophylls, the samples were stained with wheat germ agglutinin (WGA). Sample leaves were considered recombinant BSMV: $\gamma$, BSMV:TaATG8j-1s and BSMV:TaATG8j-2s that had been previously inoculated with pathotype CYR23. (A) Leaves were observed at 24, 48 and $72 \mathrm{hpi}$. The infected sites were observed using an epifluorescence microscope. HMC: haustorial mother cell; SV: substomatal vesicle; IH: infection hyphae. Each result was considered from 50 infection sites. Bar, $20 \mu \mathrm{m}$; (B) Hyphal length: the distance from the joint of the substomatal vesicle to the apex of the hypha; (C) Hyphal branches: the average numbers of primary hyphae; (D) Necrotic area: quantified as the area of autofluorescence. Different letters indicate significant differences $(p<0.05)$ using the Tukey HSD test. 


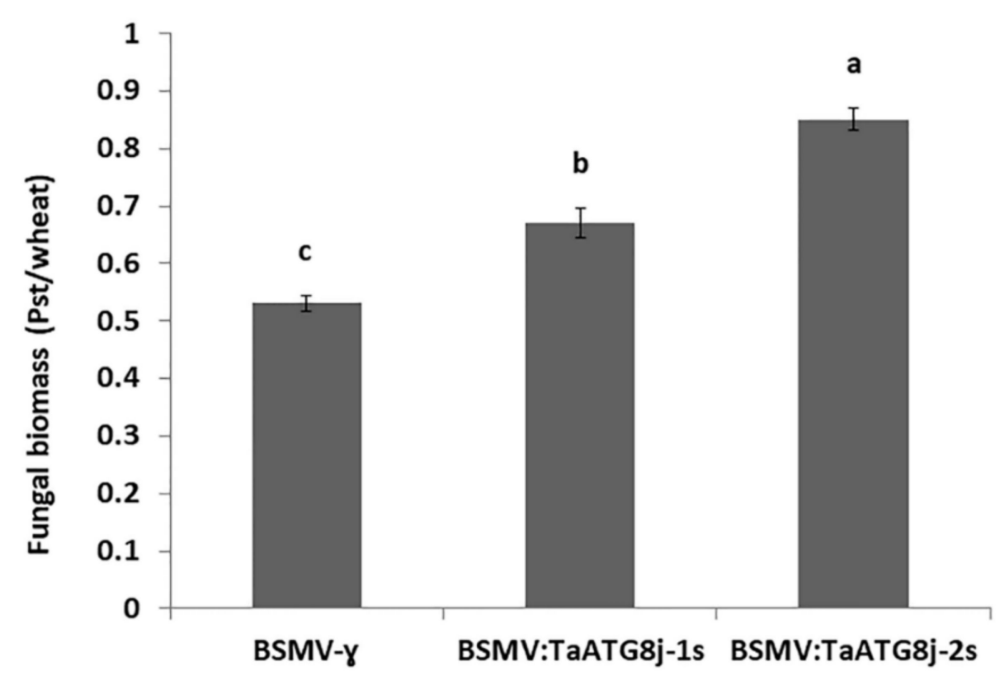

Figure 10. DNA biomass assay in TaATG8j-silenced plants challenged with the avirulent Pst pathotype CYR23. Two standard curves were generated for the accurate measurement of Pst and wheat DNA. Quantification cycle $(\mathrm{Cq})$ values are plotted against the initial copy number of template DNA $\left(10^{4}, 10^{5}\right.$, $10^{6}, 10^{7}, 10^{8}$, and $\left.10^{9}\right)$. Genomic DNA of Su11, infected with urediniospore of Pst pathotype CYR23, was used to generate the standard curves. Fungal biomass was measured by qRT-PCR on the extracted total genomic DNA from wheat leaves infected with CYR23 at $18 \mathrm{dpi}$. The ratio of the total fungal to total wheat DNA was calculated using the TaEF-1 $\alpha$ and Pst-EF genes for normalization. The letters $\mathrm{a}, \mathrm{b}$, $\mathrm{c}$ indicates the significant difference using LSD test among biomass in BSMV: $\gamma$, BSMV:TaATG8j-1s and BSMV:TaATG8j-2s.

\section{Discussion}

Autophagy is conserved among yeasts, animals and plants, and plants retain a majority of the autophagy machinery of yeast. In fact, several core protein families involved in autophagy have expanded in plants. As one of the essential autophagy-associated proteins, the expanded ATG8 family plays multifunctional roles in plants. In wheat, as a hexaploid (AABBDD) crop, nine ATG8-heterologous proteins have been reported [29]. In the present study, we identified and functionally characterized one of the ATG8 genes (TaATG8j) in wheat. Three copies of TaATG8j were located in the wheat genome. They shared high similarity with the other ATG8 members, which may suggest potential redundancy, or on the other hand, that many similar but different proteins or enzymes are required for the overall autophagy process.

During the wheat-Pst incompatible interaction, TaATG8j is specifically induced in the wheat tissue response to avirulent $P s t$, suggesting its potential involvement in the basal defense activated by avirulent rust fungus. Heterologous expression in fission yeast revealed a pro-cell-death function of TaATG8j. The silencing of TaATG8j resulted in reduced necrotic cell death caused by an avirulent Pst pathotype. During the wheat-Pst incompatible interaction, HR surrounding the infection sites with rapid and robust cell death is the main form of wheat resistance. The suppressed necrotic cell death indicated a prohibited HR in TaATG8j-knockdown plants, which led to the enhanced growth and development of $P$ st. It appears that TaATG8j functions positively to promote cell death during HR to defend against biotrophic pathogen attack. However, the overexpression of TaATG8j in $N$. benthamiana delayed cell death caused by BAX, exhibiting a pro-survival role. These results indicate that TaATG8j may play different roles under different conditions. In fact, there is still controversy about autophagic activities in cell death. Autophagy has been reported to be involved in both cell survival and cell death, which therefore to restrict or promotes PCD at the site of pathogen infection. In plants' defensive response against biotrophic or necrotrophic fungi, PR proteins control pathogen invasion [9]. In stress conditions, autophagy triggers the cell survival (antideath) mechanism to cope with the adverse situation [33,34]. In contrast, in certain physiological or developmental conditions, 
autophagy is considered a nonapoptotic (autophagic or type II) form of cell death (pro-death) [35,36]. When there is limited nutrition, autophagy promotes or restricts PCD in specific pathological and developmental situations in eukaryotic cells, maintaining the adaptive and homeostatic balance [37]. The dual role of the plant immune system diagnoses pathogen-associated molecular patterns (PAMPs) by PAMP-triggered immunity (PTI) and evolves resistance proteins, which recognize the pathogen effector proteins and induces effector-triggered immunity (ETI). However, in most of the cases, PTI and ETI are related to PCD at the site of microbial invasion, which is considered HR [38].

Effector-triggered immunity is the main resistance mode of wheat to the biotrophic stripe rust fungus. As the typical characteristics of ETI, we measured HR, number of branches, hyphal length, and necrotic areas to determine the capability of Pst to form colonies in inoculated wheat tissue. The accumulation of PR proteins significantly decreased when TaPR1, TaPR2 and TaSOD primers were used in TaATG8j-knockdown plants (Figure 8), supporting a positive role of TaATG8j in the activation of the plant resistance response. For further confirmation of the function of TaATG8j, we assayed the fungal biomass in both BSMV:TaATG8j-1s- and BSMV:TaATG8j-2s-knockdown plants compared with the control (BSMV: $\gamma$ ) following infection with the avirulent Pst pathotype CYR 23. The Pst biomass in the knockdown plants was significantly increased (Figure 10), suggesting that TaATG8j proteins contribute to resistance to Pst by limiting Pst growth.

Determination of the subcellular localization may provide information about the functions of TaATG8j. In A. thaliana, ATG8 proteins penetrate the autophagosomes and vacuoles and then degrade or become attached to the outer membrane of the vacuoles, followed by removal from the outside membrane [18]. ATG8 proteins are scattered throughout a preautophagosomal structure under basal and low-nitrogen conditions [39]. ATG8 proteins participate in both autophagy and cytoplasm-to-vacuole transportation [20]. In wheat, four types of ATG8 proteins are distributed in punctate, possibly autophagosomal structures, suggesting that they may be recruited to autophagic membranes and then participate in autophagy [29]. In the present study, TaATG8j proteins were found also to be randomly distributed throughout the cytoplasm. The localization of TaATG8j proteins in the cytoplasm may suggest its function in autophagic membrane biogenesis. Whether the decreased defense in TaATG8j-knockdown plants is due to the altered autophagy activity needs to be further determined.

\section{Materials and Methods}

\subsection{Cloning and Sequence Analyses of TaATG8j}

Based on the expressed sequence tag (EST) sequence (Accession No. GR302394.1) from the cDNA library of a compatible wheat-Pst interaction [40], the primers TaATG8j-PB-F and TaATG8j-PB-R (Table S1) were used to clone the open reading frame (ORF) of TaATG8j. The amino acid sequence and conserved domains of TaATG8j were analyzed on website for protein translation (Available online: http: / / insilico.ehu.es/translate/) and NCBI (Available online: https: / / www.ncbi.nlm.nih.gov/ Structure/cdd/wrpsb.cgi/), respectively. Multi-sequence alignment was conducted using DNAMAN 6.0 software (Lynnon Biosoft, San Ramon, CA, USA). Phylogenetic analysis of TaATG8j protein and other proteins was carried out using the neighbor-joining method with 1000 replicate bootstrap values, using the MEGA7 software (Available online: https:/ /www.megasoftware.net/) (Figures 1 and 2).

\subsection{Plant and Fungal Materials}

The wheat variety Suwon 11, N. benthamiana and Pst pathotypes CYR 31 (virulent) and CYR23 (avirulent) were collected from State Key Laboratory, Northwest A\&F University, Yangling, China, and were used in this study. Su11, carrying the stripe rust resistance gene $Y r S u$, is resistant to CYR23 but susceptible to CYR31 [41]. Wheat plants were grown and inoculated with the Pst pathotypes following the methods as described by Kang and Li [42]. The first leaves of wheat at the two-leaf stage were artificially inoculated separately with the fresh urediniospores of the Pst pathotypes CYR23 
and CYR31, whereas the mock (control plant) was treated with sterile water. After inoculation, the wheat seedlings were incubated in a dark chamber for $24-36 \mathrm{~h}$ at $100 \%$ relative humidity and $15^{\circ} \mathrm{C}$ temperature under a 16-h photoperiod with florescent white light. For RNA extraction, inoculated wheat leaves were sampled at $0,6,12,24,48$, and $120 \mathrm{~h}$ post-inoculation (hpi). At each time point, sampled leaves were immediately submerged in liquid nitrogen and preserved at $-80{ }^{\circ} \mathrm{C}$ prior to RNA extraction. For each time point, three biological replications were performed.

\subsection{Extraction of RNA, cDNA Synthesis and qRT-PCR Analysis}

RNA was extracted from the collected wheat leaves using the TRIzol reagent method (Invitrogen, Carlsbad, CA, USA), according to the guidelines of the manufacturer. The quality of RNA was determined by gel electrophoresis. Additionally, the RNA concentration was determined using a NanoDrop ${ }^{\mathrm{TM}} 1000$ spectrophotometer (Thermo Fisher Scientific, Waltham, MA, USA). The cDNA was produced from $2 \mu \mathrm{g}$ of total RNA with oligo (dt)18 primers using the RevertAid First Stand cDNA Synthesis kit (Thermo Fisher Scientific, Waltham, MA, USA; Available online: www.thermofisher.com/order/catalog/product/K1621) following the manufacturer's instructions. On the basis of the subgenomic alignment to assess Pst expression, we designed specific primers from subgenomes $2 \mathrm{~A}, 2 \mathrm{~B}$ and 2D, and then qRT-PCR was performed (Figure 3). The expression of TaATG8j-2AS, TaATG8j-2BS and TaATG8j-2DS in relation to the compatible and incompatible interactions between wheat and Pst was quantified using qRT-PCR performed on a CFX Connect ${ }^{\mathrm{TM}}$ Real-time PCR Detection System (Singapore). The relative expression was controlled using the wheat elongation factor gene TaEF-1 $\alpha$ (GenBank accession no. Q03033) and was quantified using the comparative $2^{-\Delta \Delta C t}$ method [43]. All reactions were performed in triplicate and with three biological replications. The primers used for qRT-PCR are listed in Table S1.

\subsection{Subcellular Localization and Immunoblotting of GFP-TaATG8j}

To investigate the subcellular localization of TaATG8j, the ORF of TaATG8j was sub cloned into the $\mathrm{P}^{\text {BinGFP2 }}$ vector using the specific primers TaATG8j-PB-F and TaATG8j-PB-R. Furthermore, the common primers $\mathrm{P}^{\mathrm{BinGFP} 2}-\mathrm{F}$ and $\mathrm{P}^{\mathrm{BinGFP} 2}-\mathrm{R}$ were used to confirm the ligation of the ORF into the $\mathrm{P}^{\mathrm{BinGFP2}}$-GFP vector, which was introduced into the Agrobacterium tumefaciens strain GV3101 by electroporation. When the $\mathrm{OD}_{600}$ of the culture medium reached $0.7-0.8$ (4-5 weeks), we infiltrated the culture into $N$. benthamiana leaves. Infiltrated plants were incubated in a growth chamber under a 16-h/8-h photoperiod at $22{ }^{\circ} \mathrm{C}$. Two days post-infiltration, leaf tissues were sampled for microscopic study using DAPI (concentration of $5 \mu \mathrm{g} \cdot \mathrm{mL}^{-1}$ ) to detect whether GFP-TaATG8j was in nuclei. Additionally, hypertonic solution (0.8 M D-mannitol, MW: 182.17) was used to identify the specific position of GFP-TaATG8j. The GFP level of the empty vector and TaATG8j was observed under a fluorescence microscope (Olympus BX-53F, Olympus Corporation, Tokyo, Japan).

For Western blotting, leaves of $N$. benthamiana carrying eGFP-TaATG8j-PB-3101 were sampled and ground in liquid nitrogen. The total protein was extracted using a protein extraction kit (Solarbio, Beijing Solarbio Science and Technology Co. Ltd., Beijing, China) following the manufacturer's guidelines. Western blotting was performed using $1 \times$ SDS-PAGE. Proteins were then transferred onto cellulose blotting membranes (pore size $0.45 \mathrm{~mm}$, Bio-Rad, Hercule, CA, USA), which were incubated in blocking buffer ( $5 \%$ BD-Difco skim milk in $1 \times$ TBS and $0.05 \%$ Tween 20 ) for $2 \mathrm{~h}$. The membranes were then incubated with mouse primary antibody (anti-eGFP antibody, Sigma-Aldrich, Shanghai, China) at 1:1000 dilutions to detect the eGFP fusion protein. Moreover, secondary antibody (anti-mouse antibody at 1:5000 dilution, Sigma-Aldrich Co.) and chemiluminescence substrate were used to visualize proteins (Sigma, Tokyo, Japan).

\subsection{Agrobacterium-Mediated Transient Expression of TaATG8j in N. benthamiana}

The coding region of TaATG8j was amplified with the specific primers TaATG8j-ClaI-F and TaATG8j-SalI-R (Table S1) and cloned via ClaI and SalI into the potato virus X (PVX) vector PGR106, resulting in the recombinant PVX-TaATG8j. The reconstructed vectors PVX-Empty Vector (EV), 
PVX-Avr1b, PVX-BAX and recombinant PVX-TaATG8j were transformed separately into A. tumefaciens (GV3101) via electroporation. The transformed A. tumefaciens strains carrying PVX-EV, PVX-TaATG8j, PVX-BAX or PVX-Avr1b were cultured in LB medium with kanamycin $\left(30 \mu \mathrm{g} \mathrm{mL} \mathrm{L}^{-1}\right)$ and rifampicin $\left(30 \mu \mathrm{g} \cdot \mathrm{mL}^{-1}\right)$ at $28^{\circ} \mathrm{C}$ for $24-48 \mathrm{~h}$. During the log phase, cells were collected by centrifugation at room temperature, washed 2-3 times with $10 \mathrm{mM} \mathrm{MgCl}_{2}$ and suspended to an $\mathrm{OD}_{600}$ of $0.2-0.3$ with infiltration medium $\left(10 \mathrm{mM} \cdot \mathrm{MgCl}_{2}\right)$. The suspensions were kept in darkness at room temperature for 3-4 h prior to infiltration. A. tumefaciens carrying PVX-EV, PVX-Avr1b, or PVX-TaATG8j were infiltrated into both sides of $N$. benthamiana leaves with a syringe without a needle. Twenty-four hours later, an A. tumefaciens strain carrying PVX-BAX was injected into the same position in one part of the leaf and was photographed 5 and 6 days after infiltration. Three biological replications were performed, and for each replicate, four $N$. benthamiana leaves were tested.

\subsection{Overexpression of TaATG8j in Yeast}

The coding sequence of TaATG8j was amplified using primers TaATG8j-Sal I-F and TaATG8j-Sma I-R and cloned into the SalI- and SmaI-digested pREP3X vector. The reconstructed pREP3X_BAX, pREP3X and recombinant pREP3X_TaATG8j were transformed into fission yeast (S. pombe) by electroporation; $5 \mu \mathrm{g} \mathrm{mL}{ }^{-1}$ thiamine (VB) was used to repress the nmt promoter in the pREP3x vector. The positively transformed yeast cells were incubated for $34 \mathrm{~h}$ in fresh liquid SD (-Leu) with or without thiamine with a starting optical density at $\mathrm{OD}_{600}: 0.2$. The fission yeast cells were then sampled at $14,18,22,26,30$ and $34 \mathrm{~h}$ post-incubation. The dead cells were stained with trypan blue at a concentration of $10 \mu \mathrm{M}$ [44] and then counted using a hemocytometer under an OLYMPUS BX-53F microscope. The dead yeast cells appeared blue, and the percentage of dead yeast cells to total yeast cells was determined in at least 10 fields of view. The total alive yeast cells were also counted with and without using VB.

\subsection{BSMV-Mediated Silencing of TaATG8j in Wheat-Pst Interactions}

The cDNA sequence of TaATG8j was aligned with the T. aestivum cv. Chinese Spring (CS) genome using the service provided by the International Wheat Genome Sequencing Consortium (Available online: http://wheat-urgi.versailles.inra.fr/Seq-Repository/BLAST/). Two fragments (105 bp from the coding region and $101 \mathrm{bp}$ from the coding and $3^{\prime}$ untranslated regions) exhibiting the highest polymorphism within the gene family and the lowest sequence similarity to other genes were chosen to reconstruct gRNA-based derivative plasmids. The two chosen fragments used for silencing were amplified with the specific primers TaATG8j-PacI-F1, TaATG8j-NotI-R1, TaATG8j-PacI-F2 and TaATG8j-NotI-R2 (Supplementary Table S1) and sub-cloned into $\gamma$-RNA of barley stripe mosaic virus (BSMV):RNAs via the NotI and PacI restriction sites to construct the recombinant BSMV:TaATG8j-1s and BSMV:TaATG8j-2s plasmid vectors. The silencing construct plasmids were linearized, and then BSMV:RNA was prepared using an in vitro RNA transcription kit (mMESSAGEmMACHINE; Ambion). For viral inoculation, the transcripts were diluted four times, including BSMV:RNA $\alpha, \beta, \gamma, \gamma$-TaPDS, TaATG8j-1s and TaATG8j-2s. Transcript (RNA plasmid) was mixed with FES buffer [45], and then the mixtures (each leaf contained $\alpha: 0.5, \beta: 0.5, \gamma$ or $\gamma$-TaPDS or TaATG8j- $1 \mathrm{~s}$ or TaATG8j-2s:0.5 $\mu \mathrm{l}$ and FES buffer:9.0 $\mu \mathrm{L}$ ) were inoculated on the apical side of the second leaves at the two-leaf stage by mildly rubbing the leaf surface using a gloved finger [46]. The leaves were incubated in the dark at a high humidity at $22-24{ }^{\circ} \mathrm{C}$ for $24 \mathrm{~h}$. Subsequently, the virus-inoculated seedlings were shifted into a $23^{\circ} \mathrm{C}$ growth chamber, and the virus symptoms were observed at regular intervals. BSMV:TaPDS was used as a positive control for the infection of BSMV. At 13 days post inoculation (dpi), when apparent viral symptoms appeared, the fourth leaf of each seedling was inoculated with fresh urediniospores of CYR23 for an incompatible interaction or CYR31 for a compatible interaction, and the seedlings were incubated at $16{ }^{\circ} \mathrm{C}$ with high relative humidity. The Pst-inoculated wheat leaves were collected at $0,24,48,72$ and 120 hpi for RNA extraction and histological observation. At 15 dpi, disease symptoms first appeared, and at $18 \mathrm{dpi}$ the disease phenotype was photographed. Leaves were 
collected (only inoculated with CYR23) for biomass assay. For each assay, three replications were performed, and there were 150 seedlings for each replication.

\subsection{Expression of TaATG8j and Pathogenesis-Related Protein (PR) Genes in TaATG8j-Knockdown Plants}

The relative silencing efficiency of TaATG8j in wheat leaves inoculated with BSMV:TaATG8j-1s and BSMV:TaATG8j-2s was analyzed in comparison to BSMV: $\gamma$ using qRT-PCR at 0, 24, 48, 72 and $120 \mathrm{hpi}$ after Pst inoculation. The relative transcription levels of the wheat-pathogenicity-related $(P R)$ protein genes TaSOD (KC158224.1), TaPR1 (AAK60565) and TaPR2 (DQ090946) in the TaATG8j-knockdown plants were determined by qRT-PCR.

\subsection{Histological Study of Fungal Growth in TaATG8j-Knockdown Plants}

For histological observation, wheat leaves were decolorized in acetic acid/absolute ethanol $(1: 1 v / v)$ and then fixed and cleared in trichloroacetaldehyde hydrate until the leaves were translucent. The cleared leaf segments were examined with a fluorescence microscope (OLYMPUS BX-53F). The autofluorescence of mesophyll cells at the infected site was observed and indicated a necrotic area. The fungal structure was stained with wheat germ agglutinin (WGA) conjugated to Alexa 488 (Invitrogen, Carlsbad, CA, USA) [47]. Only the infection in which an appressorium formed over the stoma was considered an actual penetration with the formation of infection hyphae, and the necrotic areas, haustorial mother cells, hyphal branch and hyphal length were examined. At least 50 infection sites were measured in each treatment. The hyphal length, number of hyphal branches and necrotic areas were calculated using DP2-TWAIN/DP2-BSW software (Olympus Corp, Tokyo, Japan). Error bars indicate the variation among the treatments. The statistical analysis was carried out using the Tukey test $(p<0.05)$.

\subsection{Fungal Biomass Assay in TaATG8j-Knockdown Plants}

Plant leaf samples were collected at 18 days post-inoculation with Pst CYR23 and the genomic DNA was extracted using the Plant Genomic Extraction Kit (TIANGEN, Beijing, China). The quantification of the Pst biomass was performed by qRT-PCR. The genomic DNA of Su11 leaves and urediniospores of Pst CYR23 were diluted in a gradient and used to prepare standard curves. Wheat TaEF-1 $\alpha$ and the constitutively expressed Pst elongation factor Pst-EF [48] were used to quantify the wheat and Pst in the Pst-infected leaves of the BSMV:00- or BSMV:TaATG8j-inoculated plants. The two standard curves were used to perform the relative quantification of Pst and wheat genomic DNA.

\subsection{Statistical Analyses}

Mean values and standard errors were measured using Microsoft Excel, and statistical significance levels were assessed using the SPSS software (SPSS Inc. Chicago, IL, USA).

\section{Conclusions}

In conclusion, our study revealed the different roles of TaATG8j in cell death regulation in response to different stimuli. More importantly, our findings suggest that TaATG8j functions as a positive regulator of cell death in HR to promote defense against Pst. Further research is needed to explore the detailed regulatory mechanism of TaATG $8 j$ in autophagy and pathogen resistance regulation.

Supplementary Materials: The following are available online at http:/ /www.mdpi.com/1422-0067/19/6/1666/ s1.

Author Contributions: Z.K. and X.W. designed the research program. M.A.-A.M., Y.S. and P.L. conducted the experiments. M.A.-A.M. and M.N.I. analyzed the data. M.A.-A.M., C.T., M.N.I., Z.K. and X.W. wrote this manuscript. 
Acknowledgments: This research work was supported by the National Natural Science Foundation of China (No. 31471733), the National Basic Research Program of China (No. 2013CB127700), and the earmarked fund for Modern Agro-Industry Technology Research System (No. CARS-03).

Conflicts of Interest: The authors declare no conflict of interest.

\section{Abbreviations}

$\begin{array}{ll}\text { ATG } & \text { autophagy-related gene } \\ \text { Cq } & \text { quantification cycle } \\ \text { DPI } & \text { days post-inoculation } \\ \text { hpi } & \text { hours post-inoculation } \\ \text { EST } & \text { expressed sequence tag } \\ \text { GFP } & \text { green fluorescent protein } \\ \text { HR } & \text { hypersensitive response } \\ \text { PCD } & \text { programmed cell death } \\ \text { PEG } & \text { polyethylene glycol } \\ \text { qRT-PCR } & \text { quantitative real-time PCR } \\ \text { Pst } & \text { Puccinia striiformis f. sp. tritici } \\ \text { VIGS } & \text { virus-induced gene silencing }\end{array}$

\section{References}

1. Sharma, P.; Dubey, R.S. Drought induces oxidative stress and enhances the activities of antioxidant enzymes in growing rice seedlings. Plant Growth Regul. 2005, 46, 209-221. [CrossRef]

2. Xie, Y.; Kang, R.; Sun, X.; Zhong, M.; Huang, J.; Klionsky, D.J.; Tang, D. Posttranslational modification of autophagy-related proteins in macroautophagy. Autophagy 2015, 11, 28-45. [CrossRef] [PubMed]

3. Li, F; Vierstra, R.D. Autophagy: A multifaceted intracellular system for bulk and selective recycling. Trends Plant Sci. 2012, 17, 526-537. [CrossRef] [PubMed]

4. Liu, Y.; Bassham, D.C. Autophagy: Pathways for Self-Eating in Plant Cells. Annu. Rev. Plant Biol. 2012, 63, $215-237$. [CrossRef] [PubMed]

5. Klionsky, D.J. Vacuolar import of proteins and organelles from the cytoplasm. Annu. Rev. Cell Dev. Biol. 1999, 15, 1-32. [CrossRef] [PubMed]

6. Hofius, D.; Schultz, L.T.; Joensen, J.; Tsitsigiannis, D.I.; Petersen, N.H.T.; Mattsson, O.; Jørgensen, L.B.; Jones, J.D.G.; Mundy, J.; Petersen, M. Autophagic components contribute to hypersensitive cell death in Arabidopsis. Cell 2009, 137, 773-783. [CrossRef] [PubMed]

7. Liu, Y.; Schiff, M.; Czymmek, K.; Tallóczy, Z.; Levine, B.; Dinesh-Kumar, S.P. Autophagy regulates programmed cell death during the plant innate immune response. Cell 2005, 121, 567-577. [CrossRef] [PubMed]

8. Patel, S.; Dinesh-Kumar, S.P. Arabidopsis ATG6 is required to limit the pathogen- associated cell death response. Autophagy 2008, 4, 20-27. [CrossRef] [PubMed]

9. Lenz, H.D.; Haller, E.; Melzer, E.; Kober, K.; Wurster, K.; Stahl, M.; Bassham, D.C.; Vierstra, R.D.; Parker, J.E.; Bautor, J.; et al. Autophagy differentially controls plant basal immunity to biotrophic and necrotrophic pathogens. Plant J. 2011, 66, 818-830. [CrossRef] [PubMed]

10. Minina, E.A.; Bozhkov, P.V.; Hofius, D. Autophagy as initiator or executioner of cell death. Trends Plant Sci. 2014, 19, 692-697. [CrossRef] [PubMed]

11. Yue, J.; Sun, H.; Zhang, W.; Pei, D.; He, Y.; Wang, H. Wheat heterologs of yeast ATG6 function in autophagy and are implicated in powdery mildew immunity. BMC Plant Biol. 2015, 15, 95. [CrossRef] [PubMed]

12. Hafren, A.; Macia, J.L.; Love, A.J.; Milner, J.J.; Drucker, M.; Hofius, D. Selective autophagy limits cauliflower mosaic virus infection by NBR1-mediated targeting of viral capsid protein and particles. Proc. Natl. Acad. Sci. USA 2017, 114, 2026-2035. [CrossRef] [PubMed]

13. Bassham, D.C. Function and regulation of macroautophagy in plants. Biochim. Biophys. Acta Mol. Cell Res. 2009, 1793, 1397-1403. [CrossRef] [PubMed]

14. Mitou, G.; Budak, H.; Gozuacik, D. Techniques to study autophagy in plants. Int. J. Plant Genom. 2009, $2009,1-14$. [CrossRef] [PubMed] 
15. Reggiori, F.; Klionsky, D.J. Autophagic processes in yeast: Mechanism, machinery and regulation. Genetics 2013, 194, 341-361. [CrossRef] [PubMed]

16. Xie, Z.; Klionsky, D.J. Autophagosome formation: Core machinery and adaptations. Nat. Cell Biol. 2007, 9, 1102-1109. [CrossRef] [PubMed]

17. Nakatogawa, H.; Ichimura, Y.; Ohsumi, Y. Atg8, a ubiquitin-like protein required for autophagosome formation, mediates membrane tethering and hemifusion. Cell 2007, 130, 165-178. [CrossRef] [PubMed]

18. Kirisako, T.; Ichimura, Y.; Okada, H.; Kabeya, Y.; Mizushima, N.; Yoshimori, T.; Ohsumi, M.; Takao, T.; Noda, T.; Ohsumi, Y. The reversible modification regulates the membrane-binding state of Apg8/Aut7 essential for autophagy and the cytoplasm to vacuole targeting pathway. J. Cell Biol. 2000, 151, 263-275. [CrossRef] [PubMed]

19. Nair, U.; Yen, W.L.; Mari, M.; Cao, Y.; Xie, Z.; Baba, M.; Reggiori, F.; Klionsky, D.J. A role for Atg8-PE deconjugation in autophagosome biogenesis. Autophagy 2012, 8, 780-793. [CrossRef] [PubMed]

20. Klionsky, D.J.; Cregg, J.M.; Dunn, W.A.; Emr, S.D.; Sakai, Y.; Sandoval, N.V.; Sandoval, I.V. A unified nomenclature for yeast autophagy-related genes. Dev. Cell 2003, 5, 539-545. [CrossRef]

21. Hayward, A.P.; Tsao, J.; Dinesh-Kumar, S.P. Autophagy and plant innate immunity: Defense through degradation. Semin. Cell Dev. Biol. 2009, 20, 1041-1047. [CrossRef] [PubMed]

22. Seay, M.; Hayward, A.P.; Tsao, J.; Dinesh-Kumar, S.P. Something old, something new: Plant innate immunity and autophagy. Curr. Top. Microbiol. Immunol. 2009, 335, 287-306. [PubMed]

23. Yoshimoto, K.; Hideki, H.; Shusei, S.; Tomohiko, K.; Tabata, S.; Noda, T.; Ohsumi, Y. Processing of ATG8s, ubiquitin-like proteins, and their deconjugation by ATG4s are essential for plant autophagy. Plant Cell 2004, 16, 2967-2983. [CrossRef] [PubMed]

24. Dagdas, Y.F.; Pooja, P.; Nattapong, S.; Yasin, T.; Khaoula, B.; Cian, D.; Maria, E.S.; Sophien, K.; Tolga, O.B. Host autophagosomes are diverted to a plant-pathogen interface. bioRxiv 2017. [CrossRef]

25. Duan, Y.; Guo, J.; Shi, X.; Guan, X.; Liu, F.; Bai, P.; Huang, L.; Kang, Z. Wheat hypersensitive induced reaction genes TaHIR1 and TaHIR3 are involved in response to stripe rust fungus infection and abiotic stresses. Plant Cell Rep. 2013, 32, 273-283. [CrossRef] [PubMed]

26. Wang, X.; Wang, X.; Duan, Y.; Yin, S.; Zhang, H.; Huang, L.; Kang, Z. TaAbc1, a member of Abc1-like family involved in hypersensitive response against the stripe rust fungal pathogen in wheat. PLoS ONE 2013, 8, 1-8. [CrossRef] [PubMed]

27. Chandra, C.R.; Kishor, S.N.; Mithilesh, K.; Rajeev, K. Wheat Genotypes (Triticum aestivum L.) vary widely in their responses of Fertility traits to high Temperature at Anthesis. Int. Res. J. Biol. Sci. 2014, 3, 54-60.

28. Langridge, P. Genomics: Decoding our daily bread. Nature 2012, 491, 678-680. [CrossRef] [PubMed]

29. Pei, D.; Zhang, W.; Sun, H.; Wei, X.; Yue, J.; Wang, H. Identification of autophagy-related genes ATG4 and ATG8 from wheat (Triticum aestivum L.) and profiling of their expression patterns responding to biotic and abiotic stresses. Plant Cell Rep. 2014, 33, 1697-1710. [CrossRef] [PubMed]

30. Tang, C.; Wei, J.; Han, Q.; Liu, R.; Duan, X.; Fu, Y.; Huang, X.; Wang, X.; Kang, Z. PsANT, the adenine nucleotide translocase of Puccinia striiformis, promotes cell death and fungal growth. Sci. Rep. 2015, 5, 11241. [CrossRef] [PubMed]

31. Delaney, T.P. Genetic dissection of acquired resistance to disease. Plant Physiol. 1997, 113, 5-12. [CrossRef] [PubMed]

32. Van Loon, L.C.; Van Kammen, A. Polyacrylamide disc electrophoresis of the soluble leaf proteins from Nicotiana tabacum var 'Samsun' and Samsun NN. II. Changes in protein constitution after infection with tobacco mosaic virus. Virology 1970, 40, 199-211.

33. Baehrecke, E.H. Autophagy: Dual roles in life and death? Nat. Rev. Mol. Cell Biol. 2005, 6, 505-510. [CrossRef] [PubMed]

34. Kroemer, G.; Levine, B. Autophagic cell death: The story of a misnomer. Nat. Rev. Mol. Cell Biol. 2008, 9, 1004-1010. [CrossRef] [PubMed]

35. Galluzzi, L.; Vicencio, J.M.; Kepp, O.; Tasdemir, E.; Maiuri, M.C.; Kroemer, G. To die or not to die: That is the autophagic question. Curr. Mol. Med. 2008, 8, 78-91. [PubMed]

36. Kourtis, N.; Tavernarakis, N. Autophagy and cell death in model organisms. Cell Death Differ. 2009, 16, 21-30. [CrossRef] [PubMed]

37. Üstün, S.; Hafrén, A.; Hofius, D. Autophagy as a mediator of life and death in plants. Curr. Opin. Plant Biol. 2017, 40, 122-130. [CrossRef] [PubMed] 
38. Dangl, J.L.; Horvath, D.M.; Staskawicz, B.J. Pivoting the plant immune system from dissection to deployment. Science 2013, 341, 746-751. [CrossRef] [PubMed]

39. Suzuki, K.; Ohsumi, Y. Current knowledge of the pre-autophagosomal structure (PAS). FEBS Lett. 2010, 584, 1280-1286. [CrossRef] [PubMed]

40. Ma, J.; Huang, X.; Wang, X.; Chen, X.; Qu, Z.; Huang, L.; Kang, Z. Identification of expressed genes during compatible interaction between stripe rust (Puccinia striiformis) and wheat using a cDNA library. BMC Genom. 2009, 10, 586. [CrossRef] [PubMed]

41. Liu, P.; Myo, T.; Ma, W.; Lan, D.; Qi, T.; Guo, J.; Song, P.; Guo, J.; Kang, Z. TaTypA, a ribosome-binding GTPase protein, positively regulates wheat resistance to the stripe rust fungus. Front. Plant Sci. 2016, 7. [CrossRef] [PubMed]

42. Kang, Z.; Li, Z. Discovery of a normal T. type new pathogenic strain to Lovrin10. Acta Cllegii Septentr. Occident. Agric. 1984, 4, 18-28.

43. Livak, K.J.; Schmittgen, T.D. Analysis of relative gene expression data using real-time quantitative PCR and the $2^{-\Delta \Delta C T}$ method. Methods 2001, 25, 402-408. [CrossRef] [PubMed]

44. Kucsera, J.; Yarita, K.; Takeo, K. Simple detection method for distinguishing dead and living yeast colonies. J. Micro Biol. Methods 2000, 41, 19-21. [CrossRef]

45. Scofield, S.R.; Huang, L.; Brandt, A.S.; Gill, B.S. Development of a virus-induced gene-silencing system for hexaploid wheat and its use in functional analysis of the Lr21-mediated leaf rust resistance pathway 1. Plant Physiol. 2005, 138, 2165-2173. [CrossRef] [PubMed]

46. Fu, Y.; Duan, X.; Tang, C.; Li, X.; Voegele, R.T.; Wang, X.; Wei, G.; Kang, Z. TaADF7, an actin depolymerizing factor, contributes to wheat resistance against Puccinia striiformis f. sp. tritici. Plant J. 2014, 78, 16-30. [CrossRef] [PubMed]

47. Wang, C.F.; Huang, L.; Buchenauer, H.; Han, Q.M.; Zhang, H.C.; Kang, Z.S. Histochemical studies on the accumulation of reactive oxygen species $\left(\mathrm{O}^{-2}\right.$ and $\left.\mathrm{H}_{2} \mathrm{O}_{2}\right)$ in the incompatible and compatible interaction of wheat: Puccinia striiformis f. sp. tritici. Physiol. Mol. Plant Pathol. 2007, 71, 230-239. [CrossRef]

48. Zheng, W.; Huang, L.; Huang, J.; Wang, X.; Chen, X.; Zhao, J. High genome Heterozygosity and endemic genetic recombination in the wheat stripe rust fungus. Nat. Commun. 2013, 4, 1-10. [CrossRef] [PubMed]

(C) 2018 by the authors. Licensee MDPI, Basel, Switzerland. This article is an open access article distributed under the terms and conditions of the Creative Commons Attribution (CC BY) license (http://creativecommons.org/licenses/by/4.0/). 